\title{
BMJ Open Social inequalities in prevalence of diagnosed and undiagnosed diabetes and impaired glucose regulation in participants in the Health Surveys for England series
}

\author{
Alison Moody, ${ }^{1}$ Giovanna Cowley, ${ }^{2}$ Linda Ng Fat, ${ }^{1}$ Jennifer S Mindell ${ }^{1}$
}

To cite: Moody A, Cowley G, $\mathrm{Ng}$ Fat L, et al. Social inequalities in prevalence of diagnosed and undiagnosed diabetes and impaired glucose regulation in participants in the Health Surveys for England series. BMJ Open 2016;6:e010155. doi:10.1136/bmjopen-2015010155

\section{- Prepublication history and additional material is available. To view please visit the journal (http://dx.doi.org/ 10.1136/bmjopen-2015- 010155).}

Received 1 October 2015 Revised 23 December 2015 Accepted 14 January 2016

\footnotetext{
${ }^{1}$ Research Department of Epidemiology \& Public Health, UCL, London, UK

Correspondence to Alison Moody; a.moody@ucl.ac.uk
} ${ }^{2}$ Barnet Hospital, London, UK

\section{ABSTRACT}

Objectives: To ascertain the extent of socioeconomic and health condition inequalities in people with diagnosed and undiagnosed diabetes and impaired glucose regulation (IGR) in random samples of the general population in England, as earlier diagnosis of diabetes and treatment of people with IGR can reduce adverse sequelae of diabetes. Various screening instruments were compared to identify IGR, in addition to undiagnosed diabetes.

Design: 5, annual cross-sectional health examination surveys; data adjusted for complex survey design.

Setting: Random selection of private homes across England, new sample annually 2009-2013.

Participants: 5, nationally representative random samples of the general, free-living population: $\geq 1$ adult interviewed in 24254 of 36889 eligible addresses selected. 18399 adults had a valid glycated haemoglobin $(\mathrm{HbA1c})$ measurement and answered the diabetes questions.

Main outcome measures: Diagnosed diabetes, undiagnosed diabetes $(\mathrm{HbA} 1 \mathrm{c} \geq 48 \mathrm{mmol} / \mathrm{mol})$, IGR (HbA1c 42-47 mmol/mol).

Results: Overall, $11 \%$ of the population had IGR, $2 \%$ undiagnosed and $6 \%$ diagnosed diabetes. Agestandardised prevalence was highest among Asian (19\% (95\% Cl $16 \%$ to $23 \%$ ), $3 \%$ (2\% to $5 \%$ ) and $12 \%(9 \%$ to $16 \%)$ respectively) and black participants (17\% (13\% to $21 \%), 2 \%$ (1\% to $4 \%$ ) and $14 \%(9 \%$ to $20 \%$ ) respectively). These were also higher among people with lower income, less education, lower occupational class and greater deprivation. Education (OR 1.49 (95\% Cl 1.27 to 1.74) for no qualifications vs degree or higher) and income (1.35 (1.12 to 1.62) for lowest vs highest income quintile) remained significantly associated with IGR or undiagnosed diabetes on multivariate regression. The greatest odds of IGR or undiagnosed diabetes were with increasing age over 34 years (eg, OR 18.69 (11.53 to 30.28) aged 65-74 vs 16-24). Other significant associations were ethnic group (Asian (3.91 (3.02 to 5.05)), AfricanAmerican (2.34 (1.62 to 3.38)) or 'other' (2.04 (1.07 to $3.88)$ ) vs Caucasian); sex (OR 1.32(1.19 to 1.46) for men vs women); body mass index (3.54 (2.52 to 4.96)

\section{Strengths and limitations of this study}

- This study uses a nationally representative sample of the free-living English population, with 18399 participants, and non-response weighting.

- The combination of (self-reported) diagnosis and objectively measured glycated haemoglobin allowed identification of those with undiagnosed diabetes or impaired glucose regulation.

- Socioeconomic as well as health-related covariates were used to show a wide range of associations with diabetes and impaired glucose regulation.

- A weakness of the study is the single point of data collection, making direction of effect sometimes hard to ascertain.

- Despite the large sample, some subsample groups were small, and had correspondingly wider Cls, for example, undiagnosed diabetics $(n=331)$, African-American $(n=351)$, mixed $(n=182)$ and other ethnic groups $(n=122)$.

for morbidly obese vs not overweight); and waist circumference (2.00 (1.67 to 2.38) for very high vs low).

Conclusions: Social inequalities in hyperglycaemia exist, additional to well-known demographic and anthropometric risk factors for diabetes and IGR.

\section{INTRODUCTION}

Diabetes is a condition that can result in significant morbidity and mortality, ${ }^{1}$ exacerbated by the latent period of several years during which diabetes is asymptomatic and may therefore remain undiagnosed. ${ }^{2}$ During this time, people are at risk of the complications of diabetes but being undiagnosed, they do not receive treatment to reduce the risks of cardiovascular or other diabetes- 
related diseases: at the time of diagnosis, up to $50 \%$ of people with diabetes already have microvascular and macrovascular complications. ${ }^{3} 4$ Early glycaemic control can reduce complications, ${ }^{5}$ so targeted testing for diabetes is advocated by Diabetes $\mathrm{UK}^{6}$ and the American Diabetes Association (ADA). ${ }^{7}$ In 2012, the National Institute for Health and Care Excellence (NICE) published guidelines recommending targeted screening to identify undiagnosed diabetes in asymptomatic populations. $^{8}$

Recently, a further high-risk category has been recognised: people with impaired glucose metabolism but with blood glucose levels below the diabetic range, referred to in this paper as having impaired glucose regulation (IGR). Different definitions of IGR exist but an International Expert Committee on the role of glycated haemoglobin (HbA1c) in diagnosing diabetes suggested that people with $\mathrm{HbAlc}$ of $42-47 \mathrm{mmol} / \mathrm{mol}$ $(6.0-6.5 \%)^{9}$ should be included in this group. NICE adopted this recommendation in its 2012 guidance. $^{8}$ Studies have shown an annual progression rate from IGR to diabetes of $5-10 \%^{10} 11$ and that treatment can prevent or delay progression to both diabetes ${ }^{12-15}$ and its complications. ${ }^{16}{ }^{17}$ For these reasons, NICE recommends treating people with IGR, primarily with intensive lifestyle interventions but with metformin and orlistat where lifestyle changes fail or are inappropriate. ${ }^{8}$ These guidelines have not yet been incorporated into the Quality and Outcomes Framework (QOF) for general practitioners (GPs).

Socioeconomic inequalities in health and risk factors are well known, ${ }^{18}$ as is Hart's ${ }^{19}$ inverse care law, that those at highest need are least likely to receive healthcare. Rising obesity levels, which are socially patterned, ${ }^{20}$ have been paralleled by the increasing prevalence of type 2 diabetes; ${ }^{21}{ }^{22}$ information regarding trends in diagnosed diabetes is available from QOF and the National Diabetes Audit. ${ }^{23}{ }^{24}$ These databases provide information about patients, so may not accurately reflect diabetes in the general population. In particular, they do not tell us about IGR or undiagnosed diabetes, nor do they provide information about social inequalities.

Nationally representative information about those with undiagnosed diabetes and IGR is required to understand, manage and reduce the potential impact of diabetes on population health. A recent report used Health Survey for England (HSE) data to count and characterise people with non-diabetic hyperglycaemia (IGR) and assess the relative utility of four risk scores. ${ }^{25}$ We hypothesised that more deprived groups are likely to have higher prevalence of IGR and undiagnosed diabetes, both for absolute prevalence and as a proportion of all cases of diabetes. The objectives of this study were to: determine the prevalence, and trends in prevalence, of diagnosed and undiagnosed diabetes and IGR in nationally representative data from the HSE; examine socioeconomic and ethnic inequalities in IGR and undiagnosed and diagnosed diabetes; and examine the health status and biomarkers for cardiovascular disease risk in people with these conditions. We also examined the summary performance characteristics of various current screening strategies.

\section{METHODS}

\section{Participants}

The $\mathrm{HSE}^{26}$ is an annual, cross-sectional, general population survey of individuals living in private households in England, randomly selected by address. Data collection occurs throughout the year. The first stage is a health interview, including questions about diagnosed conditions, self-rated health, and measured height and weight. The second is a nurse visit, including further physical measurements, recording prescribed medication and taking biological samples. All adults in selected households are eligible for interview; all interviewed participants are eligible for the nurse visit and biological sampling. Most years, around 8000 adults have an interview and around 6000 a nurse visit; all data collection occurs in the participants' own home.

For this analysis, survey data between 2009 and 2013 (during which time core questions and measurements remained comparable) were included, to ensure subsamples (particularly people with undiagnosed diabetes) were as large as possible. Research ethics approval was obtained from the relevant National Health Service (NHS) National Research Ethics Service (NRES) committees prior to starting each year's survey.

In total, 36889 eligible households (occupied private residences) were identified, of which at least one adult was interviewed in $24254(66 \%)$ cooperating households. All 44747 adults (aged 16+) in cooperating households were eligible for interview, nurse visit and blood sample: 38761 (87\%) were interviewed, 26216 (59\%) saw a nurse and 19578 (44\%) gave a blood sample. Non-response was due to non-contacts, refusals or inability to give informed consent (due to mental capacity or language difficulties) at the individual interview or nurse stage. Blood samples were not available because of refusal, unsuccessful attempts to take blood or medical reasons for ineligibility (including pregnancy, anticoagulants or recent fits).

The analytic sample comprised 18399 adults who had a valid $\mathrm{HbA1c}$ measurement and answered the diabetes questions. The mean age was 51.3 years (SE 0.13 ); $45 \%$ were male; $53 \%$ were in households headed by manager$\mathrm{ial} /$ professional or intermediate occupations. Four per cent had missing occupation data, $15 \%$ missing income, $8 \%$ missing body mass index (BMI), $2 \%$ missing waist circumference and $<1 \%$ missing ethnicity. Missing data for these were included as separate categories, to enable inclusion of all participants. In total, 14529 participants were normoglycaemic, 2400 had IGR, 331 had undiagnosed diabetes and 1139 diagnosed diabetes. Restricting the sample to those without diagnosed diabetes yielded 17260 participants. 


\section{Data}

\section{Diabetes and IGR definitions}

Participants were grouped according to their HbA1c result and their answers to questions on diagnosed diabetes. Those who reported that their doctor had diagnosed them with diabetes (except only when pregnant), as well as those taking medication prescribed only for diabetes, were categorised as 'doctor-diagnosed diabetes'. Those not diagnosed with diabetes were categorised as 'undiagnosed diabetes' if HbAlc was $\geq 48 \mathrm{mmol} / \mathrm{mol}(>6.5 \%)$, IGR if $42-47 \mathrm{mmol} / \mathrm{mol}(6.0-$ $6.5 \%)$ and normoglycaemic if $<42 \mathrm{mmol} / \mathrm{mol}(<6.0 \%)$.

\section{Participant characteristics}

\section{Demographics and socioeconomic position}

Age was grouped from 16 to 24 years to $75+$ in 10 years age groups. Ethnicity was self-assigned from a list of the 2001 or 2011 Census categories; categories used were Caucasian, mixed, Asian, African-American and other. Equivalised household income, adjusted for the number of adults and children in the household, was divided into quintiles within each survey year. Highest educational qualification was categorised as degree or equivalent; 'A' levels/NVQ3 or other higher qualifications below degree level; other; and none. ${ }^{27}$ Occupational data were grouped into the five-category National Statistics-SocioEconomic Classification (NS-SEC) ${ }^{28}$ Area deprivation (the Index of Multiple Deprivation IMD 2007 for HSE 2009 and 2010, and IMD 2010 for HSE 2011-2013) was divided into survey year-specific quintiles. ${ }^{29}$ All data were self-reported except for area deprivation, which was assigned from the participant's postcode.

\section{Anthropometry}

BMI was calculated from height and weight measured by the trained interviewers. Waist circumference was measured by the trained nurses. BMI was first categorised as underweight $\left(<18.5 \mathrm{~kg} / \mathrm{m}^{2}\right)$, desirable $(18.5$ to $\left.<25 \mathrm{~kg} / \mathrm{m}^{2}\right)$, overweight $\left(25\right.$ to $\left.<30 \mathrm{~kg} / \mathrm{m}^{2}\right)$, obese I $(30$ to $<35 \mathrm{~kg} / \mathrm{m}^{2}$ ), obese II (35 to $<40 \mathrm{~kg} / \mathrm{m}^{2}$ ) and morbidly obese $\left(\geq 40 \mathrm{~kg} / \mathrm{m}^{2}\right)$. A second categorisation used WHO thresholds for Asian participants ${ }^{30}(<18,18$ to $<23,23$ to $\left.<27.5, \geq 27.5 \mathrm{~kg} / \mathrm{m}^{2}\right)$, reflecting their greater risk of diabetes at lower BMI levels. We subdivided the obese categories into 27.5 to $<32.5,32.5$ to $<37.5$ and $\geq 37.5 \mathrm{~kg} / \mathrm{m}^{2}$. Third, black participants were also categorised using those lower thresholds, as recommended by NICE in 2013. ${ }^{31}$ Similarly, waist circumference was first categorised as low ( $<94 \mathrm{~cm}$ in men, $<80 \mathrm{~cm}$ in women), high (men 94-102 cm, women $80-88 \mathrm{~cm}$ ) and very high (men $>102 \mathrm{~cm}$, women $>88 \mathrm{~cm}$ ). Second, an ethnic groupspecific classification was used, where the threshold for low was $<90 \mathrm{~cm}$ in Asian and black men but was unchanged for other men and for all women. Third, sexindependent international thresholds were used that are more stringent for men: low $<88 \mathrm{~cm}$, high $\geq 88 \mathrm{~cm}$ in both men and women. Finally, the NICE risk categorisation using both BMI and waist circumference was also used. ${ }^{32}$
Other health measures

Self-rated general health was based on the answer to a standard question about participants' health in general. Responses of very good and good were combined, as were very bad and bad. Nurses measured blood pressure three times after a $5 \mathrm{~min}$ rest, using an automated device, the Omron HEM 307, with 1 min intervals between each measurement. Categories of blood pressure used information on medication prescribed for blood pressure control as well as the mean of the second and third measurements, limited to participants who had not eaten, smoked, drunk alcohol or exercised in the previous $30 \mathrm{~min}$. In 2009 and 2010, a spot urine was collected for laboratory measurement of albumin: creatinine ratio (ACR). Microalbuminuria was defined as ACR $2.5-30 \mathrm{mg} / \mathrm{mmol}$ in men and $3.5-30 \mathrm{mg} / \mathrm{mmol}$ in women and macroalbuminuria as ACR $>30 \mathrm{mg} / \mathrm{mmol}$ in either sex. In each year, blood samples were taken for serum total and high-density lipoprotein (HDL) cholesterol as well as the EDTA sample for HbA1c. Urine and blood samples were posted to the Newcastle University Hospitals laboratory, Newcastle-upon-Tyne, for assay. All measurements used standard protocols which have been reported elsewhere, along with laboratory methods and quality assurance. ${ }^{33} 34$

\section{Analyses and statistics}

Weighting and complex survey design

Data were weighted for probability of address selection (smaller regions were oversampled ${ }^{31}$ ), dwelling unit selection (only one dwelling unit selected per address) and household selection (only one household selected per dwelling unit). In addition, the weights were calibrated for household non-response, and individual nonresponse to interview, nurse visit or blood sample. The HSE is designed to be representative of people living in private households: non-response weighting is used to correct for differential response compared with known demographics from the census (age, sex, household makeup, strategic health authority and social class of household reference person), and differential response to each stage of the survey. Since the analysis was limited to those with blood samples, the 'blood weights' were used.

The HSE uses a stratified clustered sample design, and should not be treated as a simple random sample. The strata variables supplied with each annual data set are not identifiable and therefore identical strata cannot be combined across years, so government office region was used as an alternative. Clusters/primary sampling units were used as archived but recoded to avoid duplicated identifiers across years (eg, cluster 1 in 2009 was a different location to cluster 1 in 2010).

\section{Analysis}

Data were analysed using IBM SPSS V.20 (with complex survey design module), with all significance tests taking account of the complex survey design (stratification and 
clustering) and weighting. Differences between groups are mentioned as being 'significant' in this paper if $\mathrm{p}<0.05$. Prevalence of diagnosed and undiagnosed diabetes, and IGR are presented as crude proportions of participants (weighted for non-response, and accounting for complex survey design), and age-standardised and sex-standardised (reweighted to give each occupation, income, deprivation and ethnic group the same age and sex profile as the general population).

Logistic regression models were created, limited to participants without diagnosed diabetes. The two outcomes were (1) IGR or undiagnosed diabetes, and (2) undiagnosed diabetes. An outcome of IGR alone was not used as any testing for IGR in clinical practice would also aim to detect undiagnosed cases of diabetes. Explanatory variables considered were demographic (age group, sex, ethnic group), socioeconomic factors and anthropometry. The main six-category obesity variable and three-category waist circumference were not collinear, with a correlation of 0.162 , so both were included in the initial model. Missing data for the explanatory variables were included as separate categories, to enable inclusion of all participants. Income quintiles, educational qualifications, NS-SEC occupational category and area deprivation quintiles were used to assess socioeconomic inequalities. Of these, only income quintiles and educational qualifications were included in the final regression models, as these were the only variables which improved the fit of the model with the addition of each socioeconomic variable. Income and educational qualifications had a correlation of 0.101 .

The current health status and biomarkers of cardiovascular risk of participants with IGR and undiagnosed or diagnosed diabetes were also compared with those of normoglycaemic participants, both as crude and age-standardised and sex-standardised proportions.

\section{Screening metrics}

We also used our data to evaluate the effectiveness of screening using different categories for BMI and/or waist circumference, criteria for NHS Health Checks ${ }^{35}$ (inviting people aged $40-75$ or aged 25 and above from certain ethnicities) and the Diabetes UK/Leicester risk score tool (but excluding family history of diabetes) ${ }^{36} 37$ as the criteria for screening to identify IGR and undiagnosed diabetes. We calculated the sensitivity, specificity, positive predictive value and negative predictive value for the various criteria in this general population sample.

The STROBE checklist was used when writing this manuscript. The raw data are available to download from the UK Data Service.

\section{RESULTS}

\section{Social inequalities in diabetes and IGR}

There were marked socioeconomic gradients in prevalence of IGR and undiagnosed and diagnosed diabetes. For area deprivation, inequalities in IGR (table 1) were masked in the crude rates (see online supplementary table S1) due to confounding by age. Inequalities in IGR by income and education were attenuated by age/ sex standardisation but remained marked, with rates of $10 \%(95 \%$ CI $8 \%$ to $11 \%)$ in the lowest and $14 \%(12 \%$ to $15 \%$ ) in the highest income quintile and $10 \%$ (9\% to $11 \%$ ) for those with 'A' level/NVQ3 or higher educational qualifications and $14 \%$ (13\% to $16 \%)$ for those with no qualifications (table 1 ). The occupational classification showed higher IGR rates in participants in semiroutine occupations or lower supervisory/technical occupations than in other groups.

Prevalence of doctor-diagnosed diabetes across the 5 years was $6 \%$, undiagnosed diabetes was $2 \%$, and a further $11 \%$ had IGR. In general, the characteristics of people with diagnosed diabetes, undiagnosed diabetes and IGR followed similar patterns: each increased with age, overweight, lower socioeconomic position, and were higher among minority ethnic groups than the white population (after age standardisation). There were some differences, for example, while both diagnosed and undiagnosed diabetes were more common among men, age-standardised prevalence of IGR was not different between the sexes (table 1 ).

\section{Predictors of IGR or undiagnosed diabetes}

Among people without diagnosed diabetes, age was the biggest risk factor, with those aged 75 and over having almost 30 times higher odds of IGR/undiagnosed diabetes (table 2). The other important associations, which each had an independent effect, were ethnicity and both general and abdominal obesity. Unlike the prevalence figures, men had a $32 \%$ higher odds of IGR than women.

Restricting the outcome to undiagnosed diabetes, similar results were seen: although the sex difference, effects of BMI and waist circumference and associations with lower education were substantially greater, the odds for black people was similar to that for white participants. However, income was no longer significant.

\section{Health status of those with IGR, undiagnosed or diagnosed diabetes}

Normoglycaemic people were generally the healthiest. Those with IGR had higher rates than normoglycaemic participants of hypertension, high total cholesterol, low HDL cholesterol, high total:HDL ratio and albuminuria (table 3). Many of these differences remained after adjusting for the different age/sex profile of the groups. The proportion with untreated hypertension was highest among those with undiagnosed diabetes; overall hypertension rates were higher among those with diagnosed or undiagnosed diabetes, and lower among normoglycaemic and IGR participants. Those with undiagnosed diabetes were also more likely to have poor levels of HDL cholesterol, and a higher total:HDL cholesterol ratio. Those with diagnosed diabetes were least likely to have high total cholesterol. 
Table 1 Prevalence of IGR, undiagnosed and diagnosed diabetes; total diabetes and per cent undiagnosed; by sociodemographic indicators, with $95 \%$ Cls

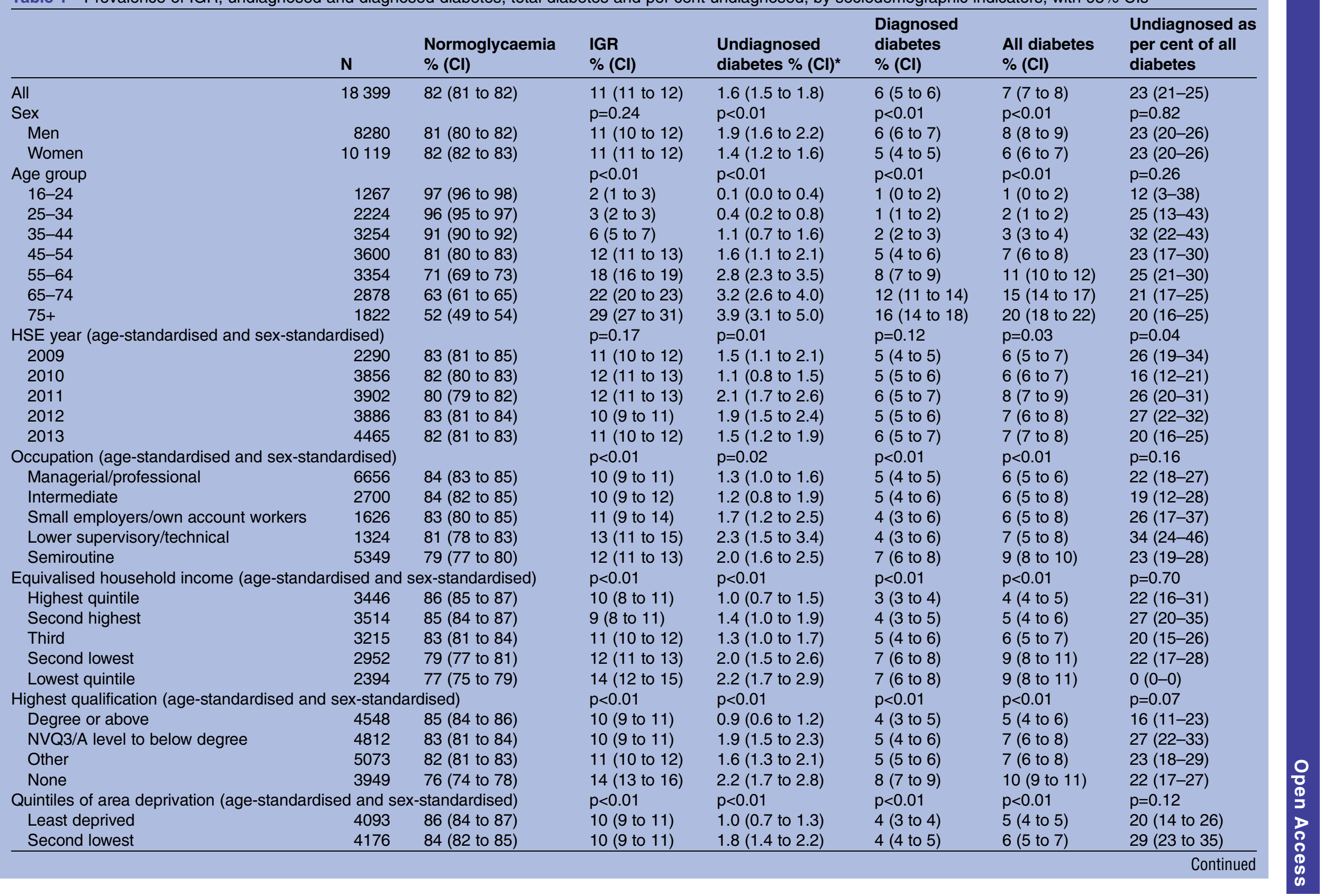




\begin{tabular}{|c|c|c|c|c|c|c|c|}
\hline & $\mathbf{N}$ & $\begin{array}{l}\text { Normoglycaemia } \\
\% \text { (CI) }\end{array}$ & $\begin{array}{l}\text { IGR } \\
\% \text { (CI) }\end{array}$ & $\begin{array}{l}\text { Undiagnosed } \\
\text { diabetes \% (CI)* }\end{array}$ & $\begin{array}{l}\text { Diagnosed } \\
\text { diabetes } \\
\%(\mathrm{Cl})\end{array}$ & $\begin{array}{l}\text { All diabetes } \\
\%(\mathrm{Cl})\end{array}$ & $\begin{array}{l}\text { Undiagnosed as } \\
\text { per cent of all } \\
\text { diabetes }\end{array}$ \\
\hline Middle & 3850 & $82(80$ to 83$)$ & $11(10$ to 12$)$ & $1.6(1.2$ to 2.1$)$ & $5(5$ to 6$)$ & $7(6$ to 8$)$ & $23(18-29)$ \\
\hline Second highest & 3354 & 79 (78 to 81$)$ & $12(11$ to 13$)$ & $1.8(1.4$ to 2.4$)$ & $7(6$ to 8$)$ & $9(8$ to 10$)$ & $20(15-26)$ \\
\hline Most deprived & 2926 & 77 (75 to 78$)$ & $13(11$ to 14$)$ & $2.1(1.7$ to 2.7$)$ & $9(8$ to 10$)$ & $11(10$ to 12$)$ & $21(16-26)$ \\
\hline \multicolumn{3}{|c|}{ Ethnic specific BMI category† (age and sex-standardised) } & $p<0.01$ & $p<0.01$ & $p<0.01$ & $p<0.01$ & $p=0.79$ \\
\hline Not overweight & 5622 & 89 (88 to 90$)$ & 8 (8 to 9$)$ & 0.6 (0.4 to 0.8$)$ & 2 (2 to 3 ) & 3 (2 to 3$)$ & 19 (14-27) \\
\hline Overweight & 6633 & 85 (84 to 86$)$ & 10 (9 to 11$)$ & 1.1 (0.9 to 1.4$)$ & 4 (3 to 4$)$ & 5 (4 to 6$)$ & 22 (18-27) \\
\hline Obese 1 & 3118 & 74 (72 to 76$)$ & 15 (14 to 17$)$ & 2.6 (2.1 to 3.2 ) & 8 (7 to 9$)$ & 11 (10 to 12$)$ & $25(19-31)$ \\
\hline Obese 2 & 1006 & 67 (64 to 71$)$ & 16 (13 to 19$)$ & 3.9 (2.8 to 5.6$)$ & 13 (11 to 15$)$ & 17 (14 to 20$)$ & $24(16-34)$ \\
\hline Morbidly obese & 429 & 55 (47 to 62 ) & 20 (15 to 25$)$ & 6.0 (3.8 to 9.4$)$ & 20 (15 to 26$)$ & 26 (20 to 32 ) & $24(15-38)$ \\
\hline \multicolumn{3}{|c|}{ Ethnic-specific waistł (age-standardised and sex-standardised) } & $\mathrm{p}<0.01$ & $\mathrm{p}<0.01$ & $p<0.01$ & $\mathrm{p}<0.01$ & $p=0.42$ \\
\hline Low & 5905 & 90 (89 to 90$)$ & $8(7$ to 9$)$ & 0.5 (0.3 to 0.7$)$ & 2 (2 to 2$)$ & $2(2$ to 3$)$ & $19(12-27)$ \\
\hline High & 4451 & 85 (84 to 87$)$ & $10(9$ to 11$)$ & $1.0(0.7$ to 1.3$)$ & 4 (3 to 4$)$ & 5 (4 to 5$)$ & $23(17-30)$ \\
\hline Very high & 7757 & 75 (74 to 77$)$ & $14(13$ to 15$)$ & $2.6(2.3$ to 3.1$)$ & 8 (7 to 9$)$ & $11(10$ to 12$)$ & $25(21-29)$ \\
\hline \multicolumn{3}{|c|}{ Ethnic group (age-standardised and sex-standardised) } & $p<0.01$ & $p<0.01$ & $p<0.01$ & $p<0.01$ & $p=0.80$ \\
\hline White & 16977 & $83(82$ to 84$)$ & $10(10$ to 11$)$ & $1.5(1.3$ to 1.7$)$ & $5(5$ to 5$)$ & $7(6$ to 7$)$ & $22(20-25)$ \\
\hline Mixed & 182 & 81 (71 to 88$)$ & 10 (5 to 17$)$ & $3.5(0.7$ to 15.6$)$ & $6(3$ to 12$)$ & $10(5$ to 19$)$ & \\
\hline Asian & 748 & 65 (61 to 70$)$ & 19 (16 to 23$)$ & $3.3(2.1$ to 5.2$)$ & 12 (9 to 16$)$ & 16 (12-20) & \\
\hline Black & 351 & 68 (61 to 74$)$ & 17 (13 to 21$)$ & 1.5 (0.6 to 3.6$)$ & 14 (9 to 20$)$ & 15 (11 to 21 ) & \\
\hline Other & 122 & $72(60$ to 81$)$ & 13 (7 to 23$)$ & $3.0(0.6$ to 14.3$)$ & $12(6$ to 23$)$ & 15 (8 to 27$)$ & \\
\hline All non-white & 1403 & 68 (65 to 72$)$ & 16 (14 to 19$)$ & 3.1 (2.0 to 4.7 ) & $12(10$ to 15$)$ & 15 (13 to 19$)$ & $21(14-30)$ \\
\hline
\end{tabular}

${ }^{*}$ To show variation in the prevalence of undiagnosed diabetes, this is presented to one $\mathrm{dp}$.

†Black and Asian participants: overweight: BMl 23 to $<27.5 \mathrm{~kg} / \mathrm{m}^{2}$; obese I: BMI 27.5 to $<32.5 \mathrm{~kg} / \mathrm{m}^{2}$; obese II: BMI 32.5 to $<37.5 \mathrm{~kg} / \mathrm{m}^{2} ; \mathrm{morbidly}$ obese: BMI $\geq 37.5 \mathrm{~kg} / \mathrm{m}^{2}$; other participants:

overweight: BMI 25 to $<30 \mathrm{~kg} / \mathrm{m}^{2}$; obese I: BMI 30 to $<35 \mathrm{~kg} / \mathrm{m}^{2}$; obese II: BMI 35 to $<40 \mathrm{~kg} / \mathrm{m}^{2}$; morbidly obese: BMI $\geq 40 \mathrm{~kg} / \mathrm{m}^{2}$.

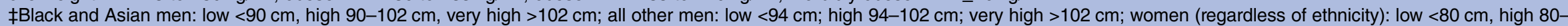

$88 \mathrm{~cm}$, very high $>88 \mathrm{~cm}$.

BMI, body mass index $\left(\mathrm{kg} / \mathrm{m}^{2}\right)$; HSE, Health Survey for England; IGR, impaired glucose regulation. 
Table 2 Logistic regression of factors associated with IGR or undiagnosed diabetes, or with undiagnosed diabetes

\begin{tabular}{|c|c|c|c|c|c|c|}
\hline & \multicolumn{3}{|c|}{ IGR or undiagnosed diabetes } & \multicolumn{3}{|c|}{ Undiagnosed diabetes } \\
\hline & $\overline{\text { OR }}$ & $95 \% \mathrm{Cl}$ & p Value & $\overline{\text { OR }}$ & $95 \% \mathrm{Cl}$ & p Value \\
\hline Female & 1 & & $<0.001$ & 1 & & $<0.001$ \\
\hline Male & 1.32 & 1.19 to 1.46 & $<0.001$ & 1.96 & 1.55 to 2.49 & $<0.001$ \\
\hline $16-24$ & 1 & & $<0.001$ & & & $<0.001$ \\
\hline $25-34$ & 1.47 & 0.87 to 2.49 & 0.154 & 3.12 & 0.64 to 15.08 & 0.158 \\
\hline $35-44$ & 3.32 & 2.02 to 5.47 & $<0.001$ & 7.43 & 1.70 to 32.52 & 0.008 \\
\hline $45-54$ & 7.85 & 4.85 to 12.70 & $<0.001$ & 11.22 & 2.70 to 46.56 & 0.001 \\
\hline $55-64$ & 14.26 & 8.91 to 22.84 & $<0.001$ & 22.74 & 5.58 to 92.72 & $<0.001$ \\
\hline $65-74$ & 18.69 & 11.53 to 30.28 & $<0.001$ & 25.51 & 6.27 to 103.71 & $<0.001$ \\
\hline $75+$ & 29.48 & 18.15 to 47.88 & $<0.001$ & 33.58 & 8.18 to 137.87 & $<0.001$ \\
\hline White & 1 & & $<0.001$ & 1 & & $<0.001$ \\
\hline Mixed & 1.11 & 0.61 to 2.02 & 0.741 & 1.66 & 0.38 to 7.30 & 0.502 \\
\hline Asian & 3.91 & 3.02 to 5.05 & $<0.001$ & 4.51 & 2.81 to 7.25 & $<0.001$ \\
\hline Black & 2.34 & 1.62 to 3.38 & $<0.001$ & 0.88 & 0.35 to 2.21 & 0.780 \\
\hline Other & 2.04 & 1.07 to 3.88 & 0.030 & 1.26 & 0.26 to 6.21 & 0.777 \\
\hline Degree or higher & 1 & & $<0.001$ & 1 & & 0.004 \\
\hline A-level/NVQ3 to below degree & 1.20 & 1.02 to 1.41 & 0.029 & 1.76 & 1.18 to 2.72 & 0.006 \\
\hline Other & 1.24 & 1.06 to 1.44 & 0.006 & 1.53 & 0.98 to 2.38 & 0.060 \\
\hline No qualifications & 1.49 & 1.27 to 1.74 & $<0.001$ & 1.69 & 1.11 to 2.57 & 0.015 \\
\hline Highest income quintile $\ddagger$ & 1 & & 0.002 & 1 & & 0.160 \\
\hline Second highest & 0.98 & 0.82 to 1.16 & 0.810 & 1.03 & 0.63 to 1.69 & 0.894 \\
\hline Middle & 1.11 & 0.94 to 1.32 & 0.230 & 0.94 & 0.58 to 1.52 & 0.808 \\
\hline Second lowest & 1.21 & 1.01 to 1.45 & 0.035 & 1.38 & 0.86 to 2.21 & 0.187 \\
\hline Lowest quintile & 1.35 & 1.12 to 1.62 & 0.001 & 1.44 & 0.88 to 2.36 & 0.148 \\
\hline Missing & 1.16 & 0.96 to 1.39 & 0.128 & 1.39 & 0.85 to 2.28 & 0.193 \\
\hline Ethnic-specific BMI categories* & & & $<0.001$ & & & $<0.001$ \\
\hline Not overweight & 1 & & & 1 & & \\
\hline Overweight & 1.02 & 0.87 to 1.20 & 0.834 & 1.18 & 0.73 to 1.91 & 0.502 \\
\hline Obese I & 1.59 & 1.31 to 1.93 & $<0.001$ & 2.56 & 1.58 to 4.14 & $<0.001$ \\
\hline Obese II & 2.05 & 1.58 to 2.65 & $<0.001$ & 4.58 & 2.64 to 7.92 & $<0.001$ \\
\hline Morbidly obese & 3.54 & 2.52 to 4.96 & $<0.001$ & 8.19 & 4.33 to 15.4 & $<0.001$ \\
\hline Not measured & 1.35 & 1.10 to 1.66 & 0.005 & 2.39 & 1.43 to 3.99 & $<0.001$ \\
\hline \multicolumn{3}{|c|}{ Ethnic-specific waist circumference categories† } & $<0.001$ & & & 0.001 \\
\hline Low waist & 1 & & & 1 & & 0.00 \\
\hline High waist & 1.41 & 1.19 to 1.67 & $<0.001$ & 2.01 & 1.06 to 3.82 & 0.033 \\
\hline Very high waist & 2.00 & 1.67 to 2.38 & $<0.001$ & 4.41 & 2.35 to 8.27 & $<0.001$ \\
\hline Not measured & 2.11 & 1.47 to 3.03 & $<0.001$ & 4.45 & 1.94 to 10.23 & $<0.001$ \\
\hline
\end{tabular}

*Black and Asian participants: overweight: BMI 23 to $<27.5 \mathrm{~kg} / \mathrm{m}^{2}$; obese I: BMI 27.5 to $<32.5 \mathrm{~kg} / \mathrm{m}^{2}$; obese II: BMI 32.5 to $<37.5 \mathrm{~kg} / \mathrm{m}^{2}$; morbidly obese: BMI $\geq 37.5 \mathrm{~kg} / \mathrm{m}^{2}$; other participants: overweight: BMI 25 to $<30 \mathrm{~kg} / \mathrm{m}^{2}$; obese I: BMI 30 to $<35 \mathrm{~kg} / \mathrm{m}^{2}$; obese II: BMl 35 to $<40 \mathrm{~kg} / \mathrm{m}^{2}$; morbidly obese: $\mathrm{BMI} \geq 40 \mathrm{~kg} / \mathrm{m}^{2}$.

†Black and Asian men: low <90 cm, high 90-102 cm, very high >102 cm; all other men: low <94 cm; high 94-102 cm; very high >102 cm; women (regardless of ethnicity): low $<80 \mathrm{~cm}$, high $80-88 \mathrm{~cm}$, very high $>88 \mathrm{~cm}$.

flncome was included for both models, although it was significantly associated only with IGR/undiagnosed diabetes.

Index of Multiple Deprivation was not included, as it did not improve the model significantly.

$\mathrm{BMI}$, body mass index $\left(\mathrm{kg} / \mathrm{m}^{2}\right)$; IGR, impaired glucose regulation.

Self-rated health showed a marked gradient, with the age-standardised proportion reporting bad or very bad health being low among normoglycaemic and IGR participants and highest in those with diagnosed diabetes.

\section{Screening instruments for IGR and/or undiagnosed diabetes}

Among those without diagnosed diabetes, a number of possible screening criteria, using information that should be readily available to individuals or their GPs, were applied. Online supplementary table S2 shows the screening characteristics in this general population sample (excluding those with diagnosed diabetes), along with the proportion of the population so identified for screening. Despite the HSE data not including family history of diabetes, the best measure examined was based on the Diabetes UK/Leicester risk score, finding $69 \%$ of people with IGR or undiagnosed diabetes with a specificity of $72 \%$ if using 'moderate risk' (score 16+).

\section{DISCUSSION}

Our study provides up-to-date information on prevalence and trends in prevalence of diabetes, undiagnosed 
Table 3 Prevalence of health conditions by glycaemia category

\begin{tabular}{|c|c|c|c|c|c|c|c|c|}
\hline & \multicolumn{4}{|c|}{ Unadjusted (crude) prevalence } & \multicolumn{4}{|c|}{ Age-standardised and sex-standardised prevalence } \\
\hline & $\begin{array}{l}\text { Normoglycaemia } \\
\text { (\%) }\end{array}$ & $\begin{array}{l}\text { IGR } \\
(\%)\end{array}$ & $\begin{array}{l}\text { Undiagnosed } \\
\text { diabetes (\%) }\end{array}$ & $\begin{array}{l}\text { Diagnosed } \\
\text { diabetes (\%) }\end{array}$ & $\begin{array}{l}\text { Normoglycaemia } \\
\text { (\%) }\end{array}$ & $\begin{array}{l}\text { IGR } \\
\text { (\%) }\end{array}$ & $\begin{array}{l}\text { Undiagnosed } \\
\text { diabetes (\%) }\end{array}$ & $\begin{array}{l}\text { Diagnosed } \\
\text { diabetes (\%) }\end{array}$ \\
\hline \multicolumn{9}{|l|}{ Blood pressure/hypertension } \\
\hline$<130 / 80$, no medication & 57 & 33 & 20 & 18 & 55 & 47 & 32 & 33 \\
\hline $\begin{array}{l}<140 / 90 \text { but not }<130 / 80 \text {, } \\
\text { no medication }\end{array}$ & 20 & 22 & 20 & 20 & 20 & 23 & 26 & 22 \\
\hline$\geq 140 / 90$, no medication & 12 & 16 & 26 & 12 & 13 & 13 & 24 & 9 \\
\hline$<130 / 80$, on medication & 3 & 9 & 13 & 18 & 4 & 5 & 6 & 14 \\
\hline $\begin{array}{l}<140 / 90 \text { but not }<130 / 80 \text {, } \\
\text { on medication }\end{array}$ & 3 & 8 & 9 & 14 & 3 & 5 & 4 & 12 \\
\hline$\geq 140 / 90$, on medication & 4 & 12 & 11 & 17 & 5 & 7 & 7 & 10 \\
\hline \multicolumn{9}{|l|}{ Total cholesterol } \\
\hline$<4 \mathrm{mmol} / \mathrm{L}$ & 11 & 9 & 8 & 34 & 11 & 11 & 5 & 26 \\
\hline 4 to $<5 \mathrm{mmol} / \mathrm{L}$ & 31 & 24 & 27 & 38 & 30 & 23 & 22 & 39 \\
\hline$\geq 5 \mathrm{mmol} / \mathrm{L}$ & 58 & 67 & 65 & 28 & 59 & 65 & 73 & 35 \\
\hline \multicolumn{9}{|l|}{ HDL cholesterol } \\
\hline$\geq 1 \mathrm{mmol} / \mathrm{L}$ & 90 & 85 & 70 & 75 & 90 & 80 & 65 & 81 \\
\hline$<1 \mathrm{mmol} / \mathrm{L}$ & 10 & 15 & 30 & 25 & 10 & 20 & 35 & 19 \\
\hline \multicolumn{9}{|l|}{ Total:HDL cholesterol ratio } \\
\hline$<5$ & 81 & 72 & 54 & 80 & 81 & 65 & 45 & 81 \\
\hline$\geq 5$ & 19 & 28 & 46 & 20 & 19 & 35 & 55 & 19 \\
\hline$<4$ & 61 & 48 & 33 & 59 & 60 & 42 & 24 & 59 \\
\hline$\geq 4$ & 39 & 52 & 67 & 41 & 40 & 58 & 76 & 41 \\
\hline No albuminuria & 94 & 89 & 83 & 76 & 93 & 90 & 90 & 78 \\
\hline Microalbuminuria* & 6 & 10 & 16 & 22 & 6 & 9 & 9 & 20 \\
\hline Macroalbuminuria* & 0 & 1 & 1 & 2 & 0 & 1 & 1 & 2 \\
\hline \multicolumn{9}{|l|}{ Self-reported general health } \\
\hline Very good/good & 81 & 65 & 57 & 37 & 80 & 72 & 62 & 43 \\
\hline Fair & 14 & 26 & 28 & 39 & 15 & 21 & 25 & 36 \\
\hline Very bad/bad & 5 & 9 & 15 & 24 & 5 & 7 & 13 & 21 \\
\hline
\end{tabular}

${ }^{*}$ Microalbuminuria: ACR 2.5-30 mg/mmol in men, $3.5-30 \mathrm{mg} / \mathrm{mmol}$ in women; macroalbuminuria: ACR $>30 \mathrm{mg} / \mathrm{mmol}$ in either sex.

ACR, albumin:creatinine ratio; HDL, high-density lipoprotein; IGR, impaired glucose regulation. 
diabetes and IGR in the general population and social inequalities in these. These survey data show the average prevalence of diagnosed diabetes in adults aged $16+$ in England in 2009-2013 was 6\%, the same as the prevalence reported by QOF over the 2012/2013 period among those aged $17+.^{23}$ As expected, diabetes was more prevalent with increasing age and obesity as well as among males, people of black and Asian ethnicities and those in lower socioeconomic positions. Around a quarter of people with diabetes are still undiagnosed. Consistent with previous work, ${ }^{38-42}$ HSE participants with IGR have health characteristics between those with normoglycaemia and with diabetes, supporting the idea of a continuum of disease. ${ }^{43}$ We also showed that low socioeconomic status, known to be associated with diabetes, ${ }^{45} 46$ is also associated with IGR; education was the best marker. The prevalence of people with IGR is lower than expected and appears to be static. There is a graded association of cardiovascular characteristics across the continuum of impaired glucose metabolism; a diagnosis of diabetes appears to have beneficial impacts on risk factor modification. A number of different screening criteria can each identify the majority of those with impaired glucose metabolism but support the use of a validated risk assessment tool as the most sensitive screening method.

The main strengths of this study are the analysis of data from nationally representative random samples of the free-living population, rather than limiting analysis to those in the healthcare system with diagnoses or tests of blood glucose levels. Non-response weighting, recommended as the best approach to enhancing representativeness, ${ }^{47}$ was used, making these data as generalisable as possible for England. Being a general health examination survey, the richness of data about each participant enables wider examination than a diabetes-focused study, hence the breadth of information on socioeconomic position and the range of variables that could be examined. However, all surveys are limited in the extent of the questionnaire; we had no information on family history of diabetes, one component of the Diabetes UK/Leicester risk score tool. A sizeable minority of data were missing for explanatory variables, especially income and BMI. These participants were retained in the analysis, coded as a separate 'missing' category. The nature of the study results in other limitations, particularly in how the categories of impaired glucose metabolism were defined. First, to be included in the diagnosed diabetes group, participants needed to selfreport a diagnosis or be on diabetic medication. For this reason, a proportion of diagnosed diabetics may have been missed. The effect of this is likely to be small; furthermore, if people do not report that they have diabetes and are not treating their condition, it may be appropriate to consider them as undiagnosed diabetics. Another problem is the use of a single HbAlc test to categorise participants. In practice, symptoms or a confirmatory test would often be used to diagnose diabetes in people with an HbAlc of $\geq 48 \mathrm{mmol} / \mathrm{mol}$. Applications of such strict definitions might alter the number of patients in each category but any such alteration and its impact are likely to be small at a population level. As discussed, impaired glucose metabolism is a continuum, and although categories are defined for practical reasons, all those with raised HbA1c levels are at risk and could benefit from identification and risk reduction. Although the direction of association cannot be determined in cross-sectional surveys, these are the only ethical way to monitor trends in IGR and undiagnosed diabetes; cohort studies should always release such results to their participants, thus new participants are required for these analyses.

The HSE gives unique information about undiagnosed populations and social inequalities in health, not available in routine data; until recently, prevalence estimates of undiagnosed diabetes and IGR were based on models. ${ }^{6}$ Unlike the recent Public Health England report, ${ }^{25}$ we found marked socioeconomic inequalities in IGR. They examined only deprivation quintiles but failed to adjust for confounding by age; we also examined three individual-level markers of socioeconomic position and found similar health inequalities, with education and income remaining significant in a multivariate regression model with IGR or undiagnosed diabetes as the outcome. We found the average prevalence of undiagnosed diabetes in 2009-2013 was $1.6 \%$. Approximately $22 \%$ of people with diabetes remain undiagnosed, a higher proportion than the Association of Public Health Observatories (APHO) Diabetes Prevalence Model estimates. ${ }^{6}$ This proportion has fluctuated over the 5 years, but the prevalence of both undiagnosed diabetes and IGR have not changed appreciably over this time, possibly mirroring the stabilising prevalence of obesity in adults in England. ${ }^{20}$ It is too soon to assess the impact of 2012 NICE guidance and the introduction of targeted screening for earlier diagnosis.

The average IGR prevalence was $11 \%$, with no discernible trend over our 5 years of data. This contrasts starkly with another recent study using HSE data that suggested an increase in IGR prevalence from $11.6 \%$ in 2003 to $35.3 \%$ in 2011 . $^{48}$ This is explained by the differences between definitions of IGR. We used an HbAlc range of $42-47 \mathrm{mmol} / \mathrm{mol}$, as recommended by an international expert panel, NICE and Diabetes UK, ${ }^{6} 8$ whereas Mainous et al used a range of $39-47 \mathrm{mmol} / \mathrm{mol}(5.7-$ $6.4 \%)$ as recommended by $\mathrm{ADA},{ }^{7}$ finding similar 2011 prevalence in the UK as in the USA using the same definition. ${ }^{49}$ Our own findings, using the same data set for this paper, are that using a definition of $39-47 \mathrm{mmol} /$ mol, IGR was $31.2 \%$ (30.4\% to $32.1 \%$ ) $2009-2013$, and tended to decrease since 2010 (34\%) to $28 \%$ in 2013. Overall, the proportion with $\mathrm{HbAlc} 39 \mathrm{mmol} / \mathrm{mol}$ or above was $38.4 \%$, increasing from $2009(37.7 \%)$ to 2011 $(41.2 \%)$ before decreasing again to $35.9 \%$ in 2013.

The differences between the results for the different thresholds suggest that there is an increasing prevalence 
of people with an HbA1c of $39-41 \mathrm{mmol} / \mathrm{mol}$ but not with an HBA1c of $42-47 \mathrm{mmol} / \mathrm{mol}$. There are two potential explanations for this. First, there may be a lag period and the impact of the increasing prevalence of those with lower range IGR is yet to be felt. The second explanation is that people with lower range IGR do not necessarily develop increasingly deranged glucose metabolism, meaning a change in prevalence of this group would not necessarily be reflected in groups with higher HbA1c levels. If this is the case, it would provide significant support for the use of an HbAlc of $42 \mathrm{mmol} / \mathrm{mol}$ as the lower threshold for IGR as per current UK recommendations.

We showed a continued increase in the prevalence of diabetes over the 5 years, consistent with information from other databases. ${ }^{23}{ }^{24}$ This is unsurprising in the context of rising levels of obesity but provides concerning insight into the potential impact of this serious and costly condition on population health in the future. A large proportion of people with diabetes are still undiagnosed, so do not benefit from the potential advantages that a diagnosis carries. Modelling studies have suggested a benefit in using screening to detect early diabetes. ${ }^{50}{ }^{51}$ In contrast, recent data from the ADDITION trial ${ }^{52}$ does not show a reduction in mortality with screening for diabetes. In terms of biomarkers, our data support the assumption that a diagnosis can be beneficial, ${ }^{53}$ particularly for lipid and blood pressure modification: people who are diagnosed will benefit from QOF and guideline-driven risk factor modification, resulting in a stalling or reduction of cardiovascular risk factor progression despite advancing disease. However, self-reported health was worst in this group.

There is a clear case for identifying IGR as costeffective interventions exist to prevent or delay diabetes $^{6} 85455$ for people in this category. Our lower prevalence of IGR implies that interventions to manage this population may be more feasible and less costly than was anticipated based on an earlier study. ${ }^{38}$ IGR and undiagnosed diabetes are more prevalent in more deprived groups, even after adjusting for demographic factors and obesity. Undiagnosed diabetes as a proportion of all cases is also higher in these groups. It is recognised that individual 'agentic' interventions may widen inequalities, as disadvantaged groups are less likely to participate. ${ }^{56}$ Thus, only if GPs manage to target deprived groups successfully for detection and support with lifestyle modification, this programme could reduce social inequalities in health. Similarly, focusing screening and advice by occupational health departments on employees in lower supervisory and technical and semiroutine occupations could also reduce health inequalities and employee morbidity. Future health examination surveys are needed to monitor continuing trends in changes in national prevalence and social inequalities of IGR and undiagnosed diabetes, as clinical commissioning groups pilot and roll out detection and intervention programmes.
Twitter Follow Jennifer Mindell at @j_mindell

Acknowledgements The authors thank our colleagues at UCL and NatCen Social Research, the interviewers and nurses, and the participants in the Health Survey for England series.

Contributors AM had the original idea; all four authors prepared the analysis plan and interpreted the findings; AM and LNF conducted the analyses; AM and GC wrote the first draft of the manuscript; JSM wrote the second draft; all four authors contributed to subsequent drafts and approved the final version. All authors had full access to all of the data (including statistical reports and tables) in the study and can take responsibility for the integrity of the data and the accuracy of the data analysis.

Funding The Health Survey for England (HSE) 2009-2013 was funded by the Health and Social Care Information Centre. AM, LNF and JSM are funded to conduct the annual HSE but this specific study was not funded.

Disclaimer The funders of the HSE took no part in the decisions to undertake or publish this study, nor in its conduct and writing this paper; the views expressed are those of the authors alone.

Competing interests JSM reports grants from Health and Social Care Information Centre, outside the submitted work.

Ethics approval HSE 2009 was approved by Oxford B Research Ethics Committee (REC), ref. 08/H0605/103; HSE 2010 was approved by 0xford B REC, ref. 09/H0605/73; HSE 2011 and 2012 were approved by Oxford A REC, ref. 10/H0604/56; and HSE 2013 was approved by Oxford A REC, ref. 12/sc/ 0317.

Provenance and peer review Not commissioned; externally peer reviewed.

Data sharing statement No additional data are available.

Open Access This is an Open Access article distributed in accordance with the Creative Commons Attribution Non Commercial (CC BY-NC 4.0) license, which permits others to distribute, remix, adapt, build upon this work noncommercially, and license their derivative works on different terms, provided the original work is properly cited and the use is non-commercial. See: http:// creativecommons.org/licenses/by-nc/4.0/

\section{REFERENCES}

1. Seshasai SR, Kaptoge S, Thompson A, et al. Diabetes mellitus, fasting glucose, and risk of cause-specific death. $N$ Engl J Med 2011;364:829-41.

2. Harris MI, Klein R, Welborn TA, et al. Onset of NIDDM occurs at least 4-7 yr before clinical diagnosis. Diabetes Care 1992;15:815-19.

3. Spijkerman AM, Dekker JM, Nijpels G, et al. Microvascular complications at time of diagnosis of type 2 diabetes are similar among diabetic patients detected by targeted screening and patients newly diagnosed in general practice: the Hoorn screening study. Diabetes Care 2003;26:2604-8.

4. Harris MI, Eastman RC. Early detection of undiagnosed diabetes mellitus: a US perspective. Diabetes Metab Res Rev 2000;16:230-6.

5. Holman RR, Paul SK, Bethel MA, et al. 10-Year follow-up of intensive glucose control in type 2 diabetes. $N$ Engl $\mathrm{J}$ Med 2008;359:1577-89.

6. Diabetes UK Position Statement. Early identification of people with and at high risk of type 2 diabetes and interventions for those at high risk. London: Diabetes UK, 2014. https://www.diabetes.org.uk/ Documents/About\%20Us/What\%20we\%20say/diabetes-uk-postitionstatement-early-identification-type-2-0914.pdf (accessed 27 Aug 2015).

7. American Diabetes Association. Standards of medical care in diabetes-2013. Diabetes Care 2013;36(Suppl 1):S11-66.

8. National Institute for Health and Care Excellence. PH 38 Preventing type 2 diabetes: risk identification and interventions for individuals at high risk. London: NICE, 2012. http://guidance.nice.org.uk/PH38 (accessed 27 Aug 2015).

9. International Expert Committee. International Expert Committee report on the role of the $\mathrm{A} 1 \mathrm{C}$ assay in the diagnosis of diabetes. Diabetes Care 2009;32:1327-34.

10. Tabák AG, Herder C, Rathmann W, et al. Prediabetes: a high-risk state for diabetes development. Lancet 2012;379:2279-90. 
11. Heianza $Y$, Hara S, Arase $Y$, et al. HBA1c 5.7-6. 4\% and impaired fasting plasma glucose for diagnosis of prediabetes and risk of progression to diabetes in Japan (TOPICS 3): a longitudinal cohort study. Lancet 2011;378:147-55.

12. Diabetes Prevention Program Research Group. 10-Year follow-up of diabetes incidence and weight loss in the Diabetes Prevention Program Outcomes Study. Lancet 2009;374:1677-86.

13. Lindström J, llanne-Parikka $P$, Peltonen $M$, et al, Finnish Diabetes Prevention Study Group. Sustained reduction in the incidence of type 2 diabetes by lifestyle intervention: follow-up of the Finnish Diabetes Prevention Study. Lancet 2006;368:1673-9.

14. Gillies $\mathrm{CL}$, Abrams KR, Lambert PC, et al. Pharmacological and lifestyle interventions to prevent or delay type 2 diabetes in people with impaired glucose tolerance: systematic review and meta-analysis. BMJ 2007;334:299.

15. Li G, Zhang P, Wang J, et al. The long-term effect of lifestyle interventions to prevent diabetes in the China Da Qing Diabetes Prevention Study: a 20-year follow-up study. Lancet 2008;371:17839.

16. Chiasson JL, Josse RG, Gomis R, et al. Acarbose treatment and the risk of cardiovascular disease and hypertension in patients with impaired glucose tolerance: the STOP-NIDDM trial. JAMA 2003;290:486-94

17. Orchard MD, Fowler S, Temprosa M. Impact of intensive lifestyle and metformin therapy on cardiovascular disease risk factors in the diabetes prevention program. Diabetes Care 2005;28:888-94.

18. Marmot M, Goldblatt P. Importance of monitoring health inequalities. BMJ 2013;347:f6576.

19. Hart JT. The inverse care law. Lancet 1971;1:405-12.

20. Moody A. Adult anthropometric measures, overweight and obesity. In: Craig R, Mindell J, eds. Health Survey for England 2013. Leeds: Health and Social Care Information Centre, 2014. Chapter 10:1-17. http:// www.hscic.gov.uk/catalogue/PUB19295/HSE2014-ch9-adult-obe.pdf

21. González EM, Johansson S, Wallander MA, et al. Trends in the prevalence and incidence of diabetes in the UK: 1996-2005. $J$ Epidemiol Community Health 2009;63:332-6.

22. Mokdad AH, Ford ES, Bowman BA, et al. Prevalence of obesity, diabetes, and obesity-related health risk factors, 2001. JAMA 2003;289:76-9.

23. Health and Social Care Information Centre. Quality and Outcomes Framework (QOF) 2012/2013. England. http://www.hscic.gov.uk/ catalogue/PUB12262/qual-outc-fram-12-13-rep.pdf (accessed 27 Aug 2015).

24. National Diabetes Audit 2012-2013 Report 1: care processes and treatment targets. http://www.hqip.org.uk/assets/NCAPOP-Library/ NCAPOP-2014-15/NDA-Care-Processes-report-1-Final.pdf (accessed 27 Aug 2015)

25. National Cardiovascular Intelligence Network (NCVIN). NHS Diabetes Prevention Programme (NHS DPP) non-diabetic hyperglycaemia. London: Public Health England, 2015.

26. Mindell JS, Biddulph J, Hirani V, et al. Cohort profile: the health survey for England. Int J Epidemiol 2012;41:1585-93.

27. Office for National Statistics. Harmonised Concepts and Questions for Social Data Sources Secondary Principles version 3.2. http:// www.ons.gov.uk/ons/guide-method/harmonisation/ secondary-set-of-harmonised-concepts-and-questions/index.html (accessed 14 Dec 2015)

28. Office for National Statistics. Soc2010 user manual. http://www.ons.gov uk/ons/guide-method/classifications/current-standard-classifications/ soc2010/soc2010-volume-3-ns-sec--rebased-on-soc2010--user-manual/ index.html (accessed 14 Dec 2015).

29. Department for Communities and Local Government. The English Indices of Deprivation 2010. https://www.gov.uk/government/ uploads/system/uploads/attachment_data/file/6871/1871208.pdf (accessed 14 Dec 2015)

30. WHO expert consultation. Appropriate body-mass index for Asian populations and its implications for policy and intervention strategies. Lancet 2004;363:157-63. http://www.sciencedirect.com/science/ article/pii/S0140673603152683 (accessed 13 Aug 2015).

31. National Institute of Health and Care Excellence. Assessing body mass index and waist circumference thresholds for intervening to prevent ill health and premature death among adults from black, Asian and other minority ethnic groups in the UK. London: NICE, 2013. http:// www.nice.org.uk/guidance/PH46 (accessed 13 Aug 2015).

32. National Institute of Health and Care Excellence. Obesity: identification, assessment and management of overweight and obesity in children, young people and adults. London: NICE. http://www.nice. org.uk/guidance/cg189/chapter/1-recommendations\#identification-andclassification-of-overweight-and-obesity (accessed 13 Aug 2015).

33. Craig R, Mindell J, Hirani V. Health Survey for England 2010. Volume 2. Methods and documentation. Leeds: Health and Social Care Information Centre, 2011.
34. Craig R, Mindell J, eds. Health Survey for England 2013. Volume 2. Methods and documentation. Leeds: Health and Social Care Information Centre, 2014.

35. NHS Health Check. http://www.healthcheck.nhs.uk/ (accessed 27 Aug 2015)

36. Diabetes UK. Diabetes risk score. https://riskscore.diabetes.org.uk start (accessed 27 Aug 2015).

37. Gray LJ, Taub NA, Khunti K, et al. The Leicester Risk Assessment score for detecting undiagnosed type 2 diabetes and impaired glucose regulation for use in a multiethnic UK setting. Diabet Med 2010;27:887-95.

38. Garber AJ, Handelsman Y, Einhorn D, et al. Diagnosis and management of prediabetes in the continuum of hyperglycemia: when do the risks of diabetes begin? A consensus statement from the American College of Endocrinology and the American Association of Clinical Endocrinologists. Endocr Pract 2008;14:933-46.

39. Gupta AK, Brashear MM, Johnson WD. Coexisting prehypertension and prediabetes in healthy adults: a pathway for accelerated cardiovascular events. Hypertens Res 2011;34:456-61.

40. Qi Q, Liang L, Doria A, et al. Genetic predisposition to dyslipidemia and type 2 diabetes risk in two prospective cohorts. Diabetes 2012:61:745-52.

41. Anjana RM, Pradeepa R, Deepa M, et al. ICMR-INDIAB Collaborative Study Group Prevalence of diabetes and prediabetes (impaired fasting glucose and/or impaired glucose tolerance) in urban and rural India: phase I results of the Indian Council of Medical Research-INdiaDIABetes (ICMR-INDIAB) study. Diabetologia 2011:54:3022-7.

42. Bardenheier BH, Bullard KM, Caspersen $\mathrm{CJ}$, et al. A novel use of structural equation models to examine factors associated with prediabetes among adults aged 50 years and older National Health and Nutrition Examination Survey 2001-2006. Diabetes Care 2013;36:2655-62.

43. Ferrannini E, Gastaldelli A, lozzo P. Pathophysiology of prediabetes. Med Clin North Am 2011;95:327-39, vii-viii.

44. Tabak AG, Jokela M, Akbaraly TN, et al. Trajectories of glycaemia, insulin sensitivity, and insulin secretion before diagnosis of type 2 diabetes: an analysis from the Whitehall II study. Lancet 2009;373:2215-21.

45. Connolly V, Unwin N, Sherriff $P$, et al. Diabetes prevalence and socioeconomic status: a population based study showing increased prevalence of type 2 diabetes mellitus in deprived areas. $J$ Epidemiol Community Health 2000;54:173-7.

46. Espelt $\mathrm{A}$, Borrell $\mathrm{C}$, Palència $\mathrm{L}$, et al. Socioeconomic inequalities in the incidence and prevalence of type 2 diabetes mellitus in Europe. Gac Sanit 2013;27:494-501.

47. Hall J, Brown V, Nicolaas G, et al. Extended field efforts to reduce the risk of non-response bias: have the effects changed over time? Can weighting achieve the same effects? Bull Méthode Social 2013;117:5-25.

48. Mainous AG, Tanner RJ, Baker R, et al. Prevalence of prediabetes in England from 2003 to 2011: population-based, cross-sectional study. BMJ Open 2014;4:e005002.

49. Menke A, Casagrande S, Geiss L, et al. Prevalence of and trends in diabetes among adults in the United States, 1988-2012. JAMA 2015;314:1021-9.

50. Webb DR, Khunti K, Gray L, et al. Intensive multifactorial intervention improves modelled coronary heart disease risk in screen-detected type 2 diabetes mellitus: a cluster randomized controlled trial. Diabet Med 2012;29:531-40.

51. Kuo HS, Chang HJ, Chou P, et al. A Markov chain model to assess the efficacy of screening for non-insulin dependent diabetes mellitus (NIDDM). Int J Epidemiol 1999;28:233-40.

52. Simmons RK, Echouffo-Tcheugui JB, Sharp SJ, et al. Screening for type 2 diabetes and population mortality over 10 years (ADDITION-Cambridge): a cluster-randomised controlled trial. Lancet 2012;380:1741-8.

53. Charles M, Simmons RK, Williams KM, et al. Cardiovascular risk reduction following diagnosis of diabetes by screening: 1-year results from the ADDITION-Cambridge trial cohort. Br J Gen Pract 2012;62:e396-402.

54. Gillies CL, Lambert PC, Abrams KR, et al. Different strategies for screening and prevention of type 2 diabetes in adults: cost effectiveness analysis. BMJ 2008;336:1180-5.

55. Gillett M, Royle P, Snaith A, et al. Non-pharmacological interventions to reduce the risk of diabetes in people with impaired glucose regulation: a systematic review and economic evaluation. Health Technol Assess 2012;16:1-236, iii-iv.

56. Capewell S, Graham H. Will cardiovascular disease prevention widen health inequalities? PLoS Med 2010;7:e1000320. 


\section{Correction}

Moody A, Cowley G, Ng Fat L, et al. Social inequalities in prevalence of diagnosed and undiagnosed diabetes and impaired glucose regulation in participants in the Health Surveys for England series. BMJ Open 2016;6:e010155.

The UK ethnicity categories have been changed over to the USA standard terms. Since the participants were living in England, and the questionnaire asked them the standard UK categories (see below) the correct ethnic categories are as follows:

White (rather than Caucasian)

Black (rather than African-American)

Asian

And Mixed.

Therefore, 'African-American' should be replaced with 'Black' in the 'Abstract', 'Strengths and weaknesses', and 'Participant characteristics' sections; 'Caucasian' should be replaced with 'White' in the 'Abstract' and 'Participant characteristics' sections. They are correctly labelled in the tables.

BMJ Open 2016;4:e010155corr1. doi:10.1136/bmjopen-2015-010155corr1

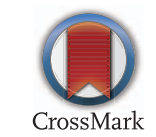

